\title{
Impact of toll-like receptor 4 deficiency on the response to uterine ischemia/reperfusion in mice
}

\author{
Larry G Thaete ${ }^{1,4}$, Xiao-Wu Qu ${ }^{1}$, Tamas Jilling ${ }^{2}$, Susan E Crawford ${ }^{3}$, Philip Fitchev ${ }^{3}$, \\ Emmet Hirsch ${ }^{1,4}$, Saira Khan ${ }^{1}$ and Mark G Neerhof ${ }^{1,4}$ \\ Departments of ${ }^{1}$ Obstetrics and Gynecology, ${ }^{2}$ Pediatrics and ${ }^{3}$ Surgery and Pathology, NorthShore University \\ HealthSystem, 2650 Ridge Avenue, Walgreen \#1507, Evanston, Illinois 60201, USA and ${ }^{4}$ Pritzker School of Medicine, \\ The University of Chicago, Chicago, Illinois, USA
}

Correspondence should be addressed to L G Thaete at Department of Obstetrics and Gynecology, NorthShore University HealthSystem; Email: Ithaete@northshore.org

L G Thaete and X-W Qu contributed equally to this work

\begin{abstract}
Our objective was to determine the role of toll-like receptor 4 (TLR4) in uterine ischemia/reperfusion (I/R)-induced fetal growth restriction (FGR). Pregnant TLR4-deficient and wild-type mice were subjected to I/R or a sham procedure. Fetal and placental weights were recorded and tissues were collected. Pep-1 (inhibits low-molecular-weight hyaluronan (LMW-HA) binding to TLR4) was used to determine whether LMW-HA-TLR4 interaction has a role in FGR. TLR4-deficient mice exhibited significantly lower baseline fetal weights compared with wild-type mice $(P<0.05)$, along with extensive placental calcification that was not present in wild-type mice. Following $I / R$, fetal and placental weights were significantly reduced in wild-type $(P<0.05)$ but not in TLR4-deficient mice. However, $I / R$ increased fetal loss $(\boldsymbol{P}<\mathbf{0 . 0 5})$ only in TLR4-deficient mice. Corresponding with the reduced fetal weights, uterine myeloperoxidase activity increased in wild-type mice $(\boldsymbol{P}<\mathbf{0 . 0 0 1})$, indicating an inflammatory response, which was absent in TLR4-deficient mice. TLR4 was shown to have a regulatory role for two anti-inflammatory cytokines: interferon-B1 decreased only in wild-type mice $(P<0.01)$ and interleukin-10 increased only in TLR4-deficient mice $(P<0.001)$, in response to I/R. Pep-1 completely prevented I/R-induced FGR $(P<0.001)$, indicating a potential role for the endogenous TLR4 ligand LMW-HA in I/R-induced FGR. In conclusion, uterine $I / R$ in pregnancy produces FGR that is dependent on TLR4 and endogenous ligand(s), including breakdown products of HA. In addition, TLR4 may play a role in preventing pregnancy loss after uterine $\mathbf{I} / \mathbf{R}$.

Reproduction (2013) 145 517-526
\end{abstract}

\section{Introduction}

Fetal growth restriction (FGR) is an important cause of fetal morbidity and mortality, as well as an underlying cause of short-term and lifelong morbidity. Nearly $40 \%$ of stillborn fetuses that are not malformed are small for gestational age. Growth-restricted neonates exhibit an increased risk of developing respiratory distress syndrome, intraventricular hemorrhage, and necrotizing enterocolitis. Growth-restricted newborns are nearly three times more likely to die in the neonatal period than normal-weight newborns (Sung et al. 1993, Piper et al. 1996, Garite et al. 2004). Among the lifelong consequences of FGR, a propensity to develop metabolic syndrome and mental health abnormalities is notable (Low et al. 1992). Despite intense investigation, the pathogenesis of FGR is not fully understood.

It has long been suggested that insufficient uteroplacental perfusion plays a central role in FGR development. Inadequate uteroplacental perfusion has been consistently observed in human FGR (Mayhew et al. 2004). Histological examination commonly reveals ischemic lesions, frequently associated with inadequate perfusion, in placentas from FGR-complicated pregnancies, as well as a correlation between the number and severity of such lesion and the severity of FGR (Salafia et al. 1995). It has been demonstrated that FGR can be induced by uterine ischemia/reperfusion $(I / R)$ in animal models (Wigglesworth 1964, Tanaka et al. 1994, Lewis et al. 2000). The involvement of inadequate perfusion and consequent $\mathrm{I} / \mathrm{R}$ - in FGR is also supported by studies on uterine vascular remodeling, the process of replacement of endothelium and smooth muscle in spiral arteries by invading trophoblasts during early pregnancy (Brosens et al. 1967). The remodeling process confers to these vessels low resistance and reduced sensitivity to vasoactive agents in order to keep perfusion to uterine and placental tissue optimized during fetal growth. 
Inadequate spiral artery remodeling, which is commonly observed in FGR and/or preeclampsia, leaves the resistance arteries anatomically intact, undilated, and responsive to vasoconstrictors (Kaufmann et al. 2003), thereby setting the stage for an inadequate response to the demand for increased blood supply to the fetus as pregnancy progresses. It is believed that once the supplyand-demand balance is lost, inadequate uteroplacental perfusion will develop into $I / R$, resulting in the production of vasoconstrictive substances that will promote a vicious cycle leading to FGR.

Inflammatory factors and their byproducts have been implicated in the pathology of I/R-induced FGR (e.g. adhesion molecules (Miyakoshi et al. 2001), reactive oxygen species (Ishimoto et al. 1997), thromboxane (Tanaka et al. 1997), and platelet-activating factor (Thaete \& Neerhof 2006)). These can, in turn, stimulate the production of vasoactive agents such as endothelin-1 (ET-1), which has been shown to be involved in the pathophysiology of FGR (Thaete \& Neerhof 2006). However, the mechanism for the development of an inflammatory response in $\mathrm{I} / \mathrm{R}$-challenged uterine and placental tissues still requires elucidation.

One such potential mechanism involves toll-like receptors (TLRs). TLRs are a family of transmembrane proteins that are widely expressed in various tissues. TLRs serve as sensors for diverse kinds of pathogenderived substances with repeated molecular patterns, such as bacterial lipopeptide, lipid, protein, and nucleic acid (Koga \& Mor 2010). In addition to bacterial/viral material, some TLRs (TLR4 and TLR2) may also be activated by endogenous ligands, such as hyaluronic acid (HA) degradation products, heat-shock proteins, fibrinogen, fibronectin, and high-mobility group box 1 (HMGB1) protein, as reviewed by Koga \& Mor (2010). After binding ligands, TLRs initiate an innate immune response through the activation of multiple signaling pathways (roughly classified as myeloid differentiation factor 88 (MyD88) dependent and MyD88 independent) and subsequent expression of pro-inflammatory mediators and effectors (e.g. cytokines, chemokines, adhesion molecules, prostaglandin synthase, and nitric oxide synthase). Recently, increasing numbers of studies have demonstrated that TLR2 and TLR4 are involved in the development of the host innate inflammatory response in $\mathrm{I} / \mathrm{R}$-induced pathology, very likely through their interaction with endogenous agonists (Arumugam et al. 2009). TLR4 (which can bind bacterial lipopolysaccharide (LPS)) is widely expressed in the placenta (Riley \& Nelson 2010), uterus, and cervix (Gonzalez et al. 2007) and its expression is upregulated during gestation.

In this study, we examine the role of endogenous activation of TLR4 in surgically produced transient uterine $\mathrm{I} / \mathrm{R}$ challenge, which induces both FGR and an inflammatory response in gestational tissues. We herein report data showing important roles for TLR4 in pregnancy, not only as a mediator of $\mathrm{I} / \mathrm{R}$-induced inflammation and its subsequent pathological impact on fetal growth but also as an important factor in the maintenance of pregnancy during $\mathrm{I} / \mathrm{R}$.

\section{Results}

\section{Sham-treated TLR4-deficient $(\mathrm{C} 3 \mathrm{H} / \mathrm{HeJ})$ mice exhibit lower fetal weights compared with wild-type $(\mathrm{C} 3 \mathrm{H} / \mathrm{HeOuJ})$ mice}

Fetal weights in TLR4-deficient mice were significantly lower $(P<0.05)$ compared with TLR4-competent wildtype mice at the same stage of gestation, while no differences were observed in the weights of placentas between the two strains (Fig. 1).

\section{Placental calcification is prominent in TLR4-deficient mice}

Placentas from TLR4-deficient and TLR4-competent mice were compared histologically on gestation day 19 . Extensive calcification, particularly in the labyrinthine layer of $\mathrm{C} 3 \mathrm{H} / \mathrm{HeJ}$ placentas, was observed in TLR4-deficient
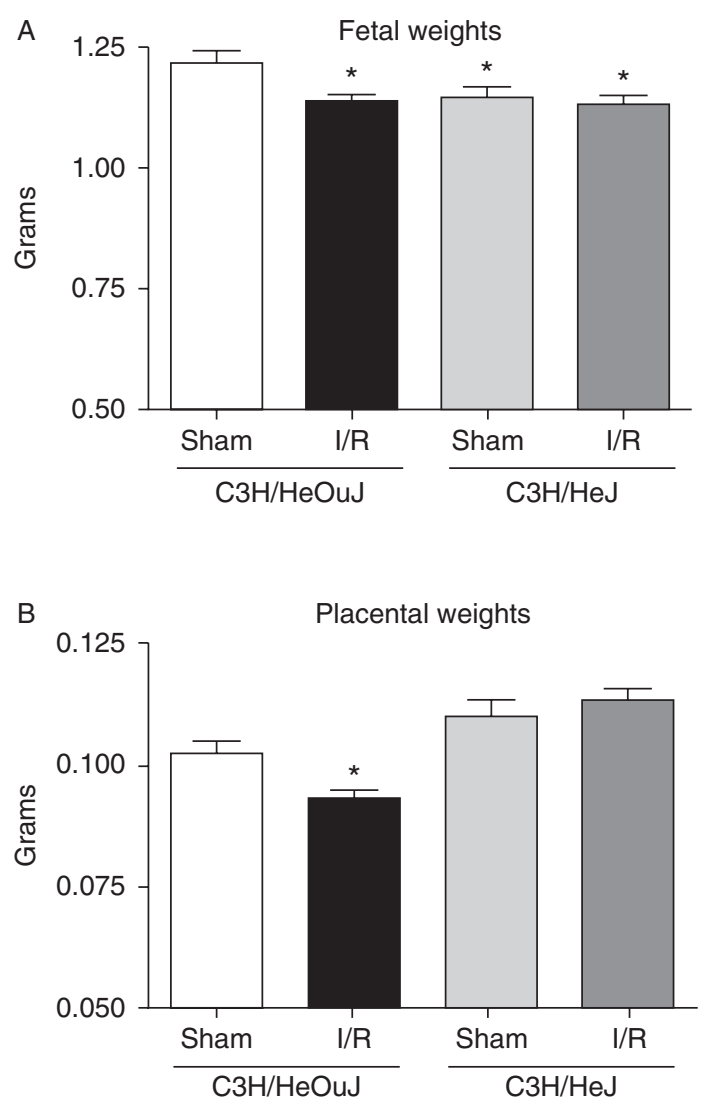

Figure 1 Fetal weight (A) and placental weight (B) in wild-type $(\mathrm{C} 3 \mathrm{H} / \mathrm{HeOuJ})$ and TLR4-deficient $(\mathrm{C} 3 \mathrm{H} / \mathrm{HeJ})$ mice in sham- and I/R-treated groups. The data are presented as mean \pm S.E.M. $* P<0.05$ compared with $\mathrm{C} 3 \mathrm{H} / \mathrm{HeOu}$ sham group, by ANOVA with Bonferroni post hoc test. 
mice but not in wild-type mice. Representative photomicrographs are shown in Fig. 2.

\section{$I / R$ challenge reduces fetal and placental weights in wild-type (C3H/HeOuJ) mice but not in TLR4-deficient $(\mathrm{C} 3 \mathrm{H} / \mathrm{HeJ})$ mice}

To evaluate the impact of $\mathrm{I} / \mathrm{R}$ on fetal growth, we examined the weight of the fetuses on the 19th day of gestation in all the pregnancies in which fetuses survived to term (pregnancy survival was $100 \%$ except in the $\mathrm{C} 3 \mathrm{H} / \mathrm{HeJ} \mathrm{l} / \mathrm{R}$ group; see below for premature delivery and fetal loss data). As expected, fetal weight was significantly lower $(P<0.05)$ in $1 /$ R-treated wild-type mice compared with mice in the sham group (Fig. 1A). In TLR4-deficient mice, no difference in fetal weights was found between I/R-treated and sham-treated animals. There was no correlation between fetal positions within the uterine horn and their respective weights in either strain.

Placental weight is an index for the development of this organ, which is pivotal for the maternal-fetal interface. $\mathrm{I} / \mathrm{R}$ produced a significant reduction in placental weight in wild-type $\mathrm{C} 3 \mathrm{H} / \mathrm{HeOuJ}$ animals $(P<0.05$, Fig. $1 \mathrm{~B})$. In contrast, no significant difference in placental weight was found between the TLR4-deficient $\mathrm{C} 3 \mathrm{H} / \mathrm{HeJ}$ mice subjected to $\mathrm{l} / \mathrm{R}$ and their sham-operated controls.

\section{Transient unilateral uterine $I / R$ challenge causes premature delivery in TLR4-deficient $(\mathrm{C} 3 \mathrm{H} / \mathrm{HeJ})$ mice but not in wild-type $(\mathrm{C} 3 \mathrm{H} / \mathrm{HeOuJ})$ mice}

The two strains of mice responded to $\mathrm{l} / \mathrm{R}$ in very different patterns. In $\mathrm{C} 3 \mathrm{H} / \mathrm{HeOuJ}$ animals, sham- and I/R-challenged alike, pregnancy continued after the surgery (as was the case in rats Thaete \& Neerhof (2006); Fig. 3). However, in the TLR4-deficient mice, the pregnancy was often interrupted after the $\mathrm{I} / \mathrm{R}$ challenge. In $53 \%$ of the $\mathrm{I} / \mathrm{R}$-treated $\mathrm{C} 3 \mathrm{H} / \mathrm{HeJ}$ mice, $100 \%$ of the fetuses were lost $24-48 \mathrm{~h}$ after the surgery through premature delivery and no fetuses remained in the uterine horns.

\section{$I / R$ challenge increases intrauterine fetal death in TLR4-deficient mice but not in wild-type mice}

In addition to fetal loss by premature birth, I/R challenge also caused an increased incidence of fetal loss by intrauterine fetal death (IUFD) per pregnancy in TLR4deficient $(\mathrm{C} 3 \mathrm{H} / \mathrm{HeJ})$ animals $(P<0.05)$, detected at necropsy at the end of the experiment (on the 19th day of gestation) (Fig. 3). In contrast, the incidence of IUFD per pregnancy was not different between sham- and l/R-treated wild-type $(\mathrm{C} 3 \mathrm{H} / \mathrm{HeOuJ})$ mice.

\section{$I / R$ challenge increases uterine myeloperoxidase activity in wild-type $(\mathrm{C} 3 \mathrm{H} / \mathrm{HeOuJ})$ mice but not in TLR4-deficient $(\mathrm{C} 3 \mathrm{H} / \mathrm{HeJ})$ mice}

$\mathrm{I} / \mathrm{R}$ is well known to activate an inflammatory response, the major pathway for the development of its pathological effects (Clarkson et al. 2005). Myeloperoxidase (MPO) is an enzyme expressed abundantly in neutrophils. Its activity in tissue is frequently used as a marker of neutrophil sequestration, a proxy for the extent of inflammatory response or vascular activation. In this study, we analyzed MPO activity in uterine and placental tissue of all treated animals with surviving pregnancies to examine whether the difference in TLR4 function has an impact on the intensity of inflammation

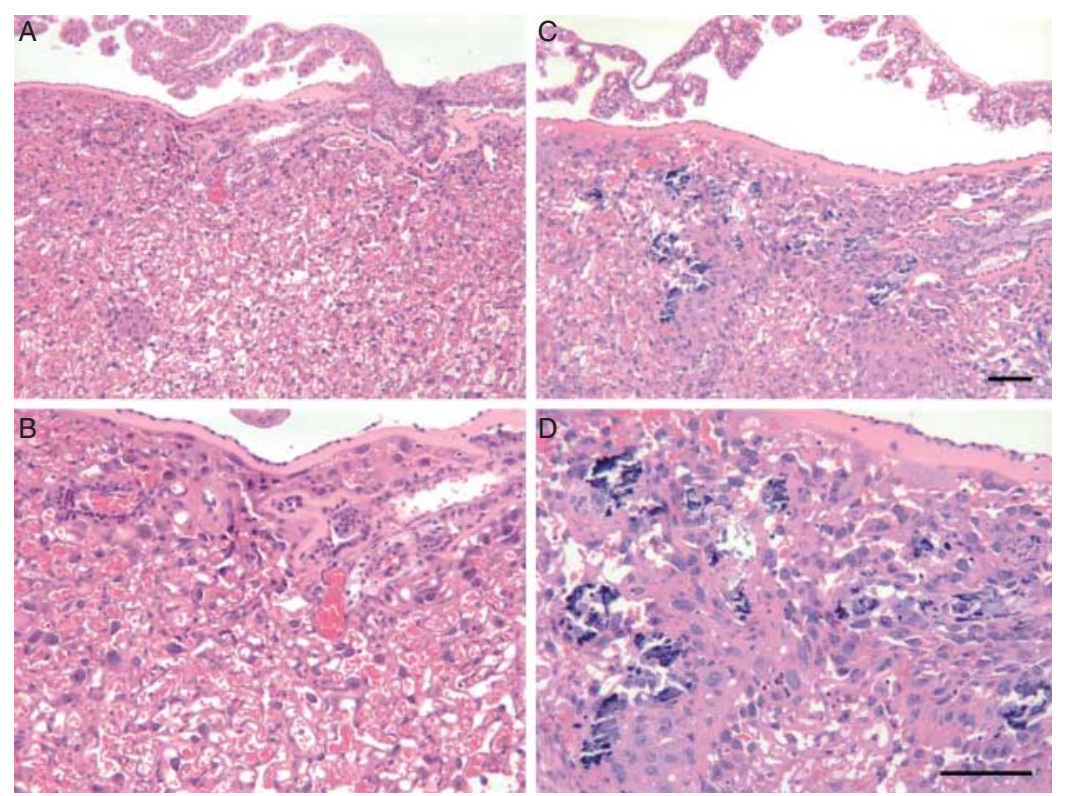

Figure 2 Placental histology. (A and B) Normal placenta of TLR4-competent $(\mathrm{C} 3 \mathrm{H} / \mathrm{HeOuJ})$ mouse and $(\mathrm{C}$ and $\mathrm{D})$ extensive placental calcification in the TLR4-deficient $(\mathrm{C} 3 \mathrm{H} / \mathrm{HeJ})$ mouse. Original magnification $=10 \times(\mathrm{A}$ and $\mathrm{C})$ and $20 \times(\mathrm{B}$ and $\mathrm{D})$; bars $=100 \mu \mathrm{m}$. 

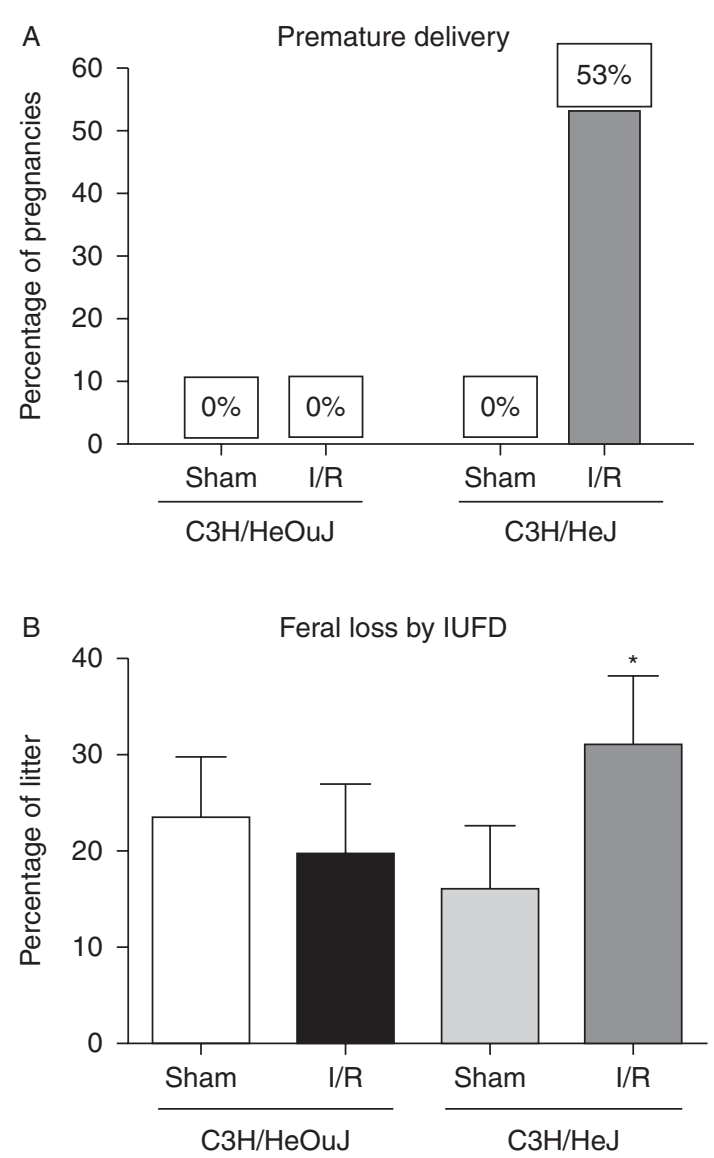

Figure 3 Premature delivery (A) and intrauterine fetal death (IUFD; B) in wild-type $(\mathrm{C} 3 \mathrm{H} / \mathrm{HeOuJ})$ and TLR4-deficient $(\mathrm{C} 3 \mathrm{H} / \mathrm{HeJ})$ mice, in sham- and I/R-treated groups ( $n=15$ pregnancies per group). IUFD data are displayed as mean \pm s.E.M. ${ }^{*} P<0.05$ compared with $\mathrm{C} 3 \mathrm{H} / \mathrm{HeJ}$ sham group, by Fisher's exact test.

in response to uterine $\mathrm{l} / \mathrm{R}$ challenge. Uterine $\mathrm{MPO}$ activity was significantly higher $(P<0.001)$ in $\mathrm{l} / \mathrm{R}$-treated $\mathrm{C} 3 \mathrm{H} / \mathrm{HeOuJ}$ mice compared with their sham controls (Fig. 4), but in TLR4-deficient $\mathrm{C} 3 \mathrm{H} / \mathrm{HeJ}$ mice, no difference was found between I/R-treated mice and their controls.

\section{Cytokine mRNA in uterine tissue: different patterns in $\mathrm{C} 3 \mathrm{H} / \mathrm{HeJ}$ and $\mathrm{C} 3 \mathrm{H} / \mathrm{HeOuJ}$ mice}

Cytokines are regulators of immune function, and their expression is partially regulated by the activity of the immune system itself. We tested whether differences in MPO activity in response to uterine $\mathrm{l} / \mathrm{R}$ challenge would be paralleled by cytokine expression profiles. The mRNA expression of several inflammation-related cytokines (revealed initially by a PCR array screening assay) in uterine tissue from experimental animals with surviving pregnancies was assessed 4 days post-I/R by real-time PCR (RT-PCR), and the results are exhibited in Fig. 5.

Uterine tissues responded to $I / R$ with an antiinflammatory profile of cytokine expression, i.e. reduced
Ifng expression $(P<0.001$ compared to sham-treated mice in each of the strains) and increased expression of $I / 10$ (TLR4-deficient strain only, $P<0.001$ ). Neither $\mathrm{I} / \mathrm{R}$ nor the status of TLR4 significantly influenced $/ / 6$ expression. Ifnb1 was reduced in the setting of $\mathrm{I} / \mathrm{R}$ in TLR4-competent mice $(P<0.01)$ but was constitutively low in the absence of functional TLR4, with and without $\mathrm{I} / \mathrm{R}(P<0.05$ and $P<0.01$ respectively).

\section{Pep-1 protects against I/R-induced FGR}

Low-molecular-weight HA (LMW-HA) degradation products have been shown to mediate I/R-induced injury by acting as endogenous TLR4 agonists (Wu et al. 2007). HA is a component of the extracellular matrix and is abundant in the uterus (particularly the cervix) (Yanagishita 1994). Given that inflammation leads to the degradation of $\mathrm{HA}$, and that the resulting LMW-HA is a TLR4 ligand, we hypothesized that LMW-HA contributes to the development of I/R-induced FGR. To test this hypothesis, we treated wild-type animals with either Pep-1 (an antagonist for LMW-HA/TLR4 interaction (Jiang et al. 2005)) or a scrambled control peptide (SP)
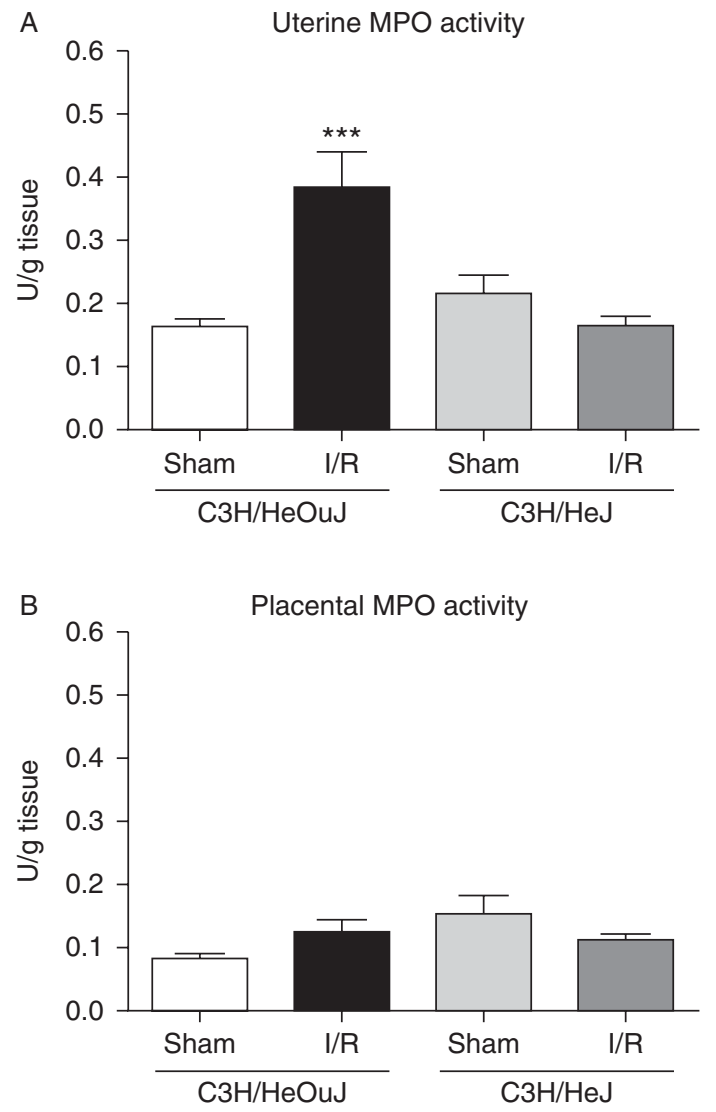

Figure $4 \mathrm{MPO}$ activity in uterine tissue (A) and placental tissue (B) from wild-type $(\mathrm{C} 3 \mathrm{H} / \mathrm{HeOuJ})$ and TLR4-deficient $(\mathrm{C} 3 \mathrm{H} / \mathrm{HeJ})$ mice, in sham- and I/R-treated groups. The data are presented as mean \pm S.E.M. *** $P<0.001$ compared with $\mathrm{C} 3 \mathrm{H} / \mathrm{HeOu}$ sham group, by ANOVA with Bonferroni post hoc test. 

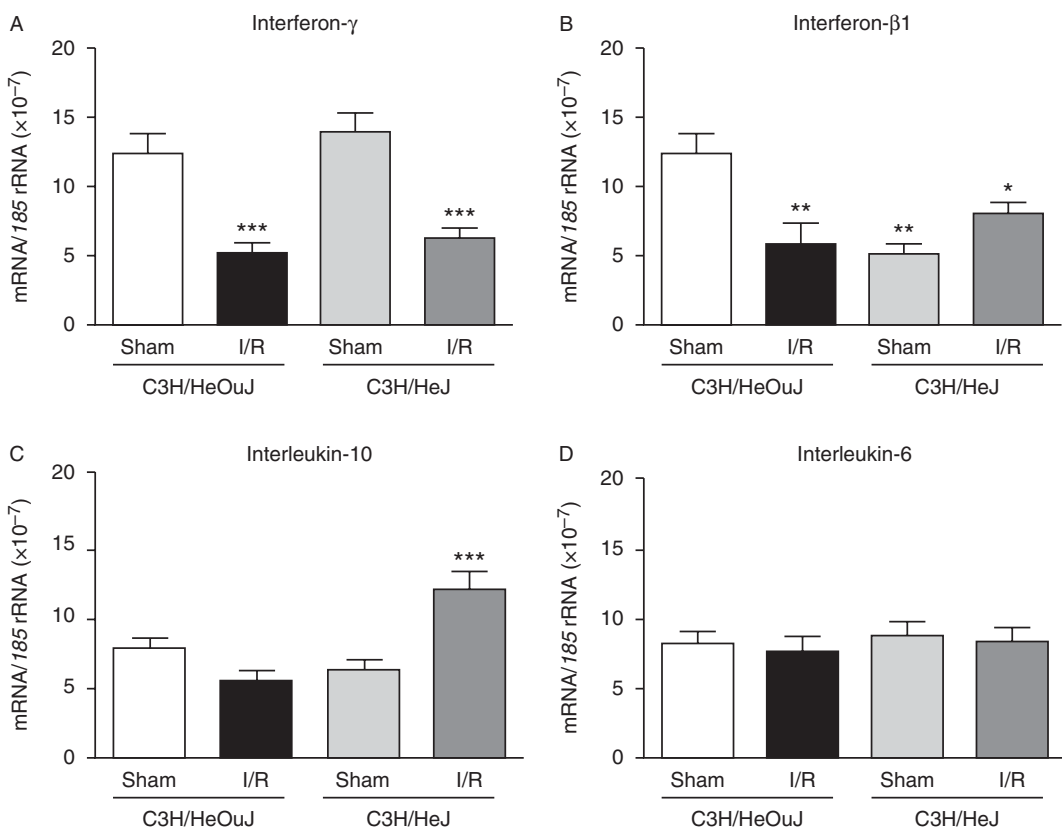

Figure 5 Uterine mRNA expression for four cytokines, determined by RT-PCR and normalized against $18 S$ rRNA. The pooled data are presented as mean \pm S.E.M. (as described for Fig. 1).

(A) $* * * P<0.001$, compared with both sham groups;

(B) $* P<0.05, * * P<0.01$, compared with $\mathrm{C} 3 \mathrm{H} / \mathrm{HeOu}$ sham group; $(\mathrm{C}) * * * P<0.001$ compared with all other groups; A, B, C, all by ANOVA with Bonferroni post hoc test. for 3 days, beginning with the day of exposure to either $\mathrm{I} / \mathrm{R}$ challenge or sham surgery. Fetal weights were measured 4 days after surgery. As expected, the scrambled peptide had no effect on fetal weight in sham-operated animals nor did it affect the reduction in fetal weight after I/R (Fig. 6). In contrast, LMW-HA antagonism with Pep-1 eliminated FGR in $\mathrm{C} 3 \mathrm{H} / \mathrm{HeOuJ}$ mice following $\mathrm{I} / \mathrm{R}$ treatment $(P<0.001)$.

\section{Discussion}

TLRs play a primary and essential role in the innate immune response to various pathogens. However, in addition to exogenous agents, endogenous TLR agonists have been identified (Koga \& Mor 2010). These endogenous TLR agonists are either structural components of tissue (such as HA (Termeer et al. 2002) and fibronectin (Okamura et al. 2001)) or molecules expressed and released during an inflammatory reaction or following cell death (heat-shock proteins 60, 70, and 90 (Chen et al. 2007) and HMGB1 (Collins et al. 2004)). They are now considered 'danger signals' because their production and release is often associated with damage to tissue integrity or with cell necrosis (Matzinger 2002).

During pregnancy, the gestational compartment may be exposed to pathogenic factors, such as bacterial or viral infection, or $\mathrm{I} / \mathrm{R}$. The innate immune machinery necessary to respond to these insults is present in gestational tissues (Gonzalez et al. 2007, Koga \& Mor 2010). Our investigation is the first to show a role for TLR4 in fetal growth in both I/R-challenged and normal pregnancy. We have also identified a novel role for the TLR4 ligand LMW-HA in I/R-induced FGR.
The fetal and placental weight results in $\mathrm{C} 3 \mathrm{H} / \mathrm{HeOuJ}$ animals demonstrate that $\mathrm{I} / \mathrm{R}$ challenge induces $\mathrm{FGR}$ as it does in rats. In TLR4-deficient animals, however, the lack of further fetal and placental weight reduction in response to $I / R$, in the setting of preexisting reduced fetal weights, is accompanied by an increased incidence of fetal death. These results not only demonstrate an important role for TLR4 in I/R-induced FGR but they also provide insight into fetal survival in response to $\mathrm{l} / \mathrm{R}$. I/R-challenged TLR4-competent fetuses survive even though growth restricted, while TLR4-deficient fetuses are more likely to die following I/R. It is possible that the innately smaller TLR4-deficient fetuses are already maximally growth restricted and that the added stress of $I / R$ easily leads to fetal death rather than to further FGR (see below). Because TLR4-deficient fetuses are inherently smaller than wild-type fetuses, and the placental size is not different between strains, FGR cannot be attributed to reduced placental growth. An important role for TLR4 signaling in $\mathrm{l} / \mathrm{R}$-induced FGR is further suggested by our observation that Pep-1 prevents I/R-induced FGR in TLR4-competent mice.

Uterine tissues at 4 days post-I/R exhibit an antiinflammatory cytokine profile that may serve to protect the pregnancy. Uterine natural killer cells are a rich source of IFNG. It has been shown that this IFNG has an important role in normal uterine vascular remodeling during pregnancy (Ashkar et al. 2000), thus possibly explaining the relative abundance of Ifng mRNA in sham-treated mice. The reduced Ifng expression following $\mathrm{I} / \mathrm{R}$ may be a reaction in the uterus to the ischemic or reperfusion process temporarily to suppress any further increase in blood flow, in order 


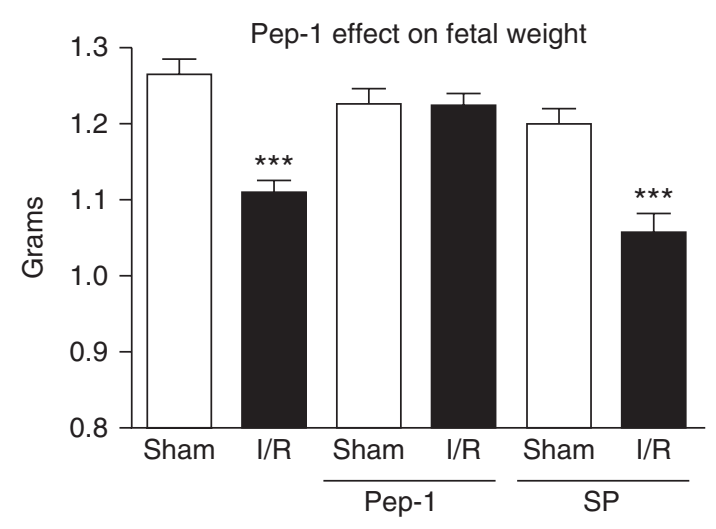

Figure 6 The effect of Pep-1 (a peptide that inhibits the binding of hyaluronic acid fragments with TLR4) and its functionless control scrambled peptide (SP) on sham- and I/R-challenged $\mathrm{C} 3 \mathrm{H} / \mathrm{HeOuJ}$ mice. The data are presented as mean \pm S.E.M. ${ }^{* * *} P<0.001$ compared with all other sham groups and with Pep- $1+\mathrm{l} / \mathrm{R}$ group, by ANOVA with Bonferroni post hoc test.

to protect the fetus from potential harmful effects of an inflammatory response (e.g. MPO). Similarly, IL10 protects the fetal-placental unit by inhibiting inflammatory cytokines, modulating trophoblast invasion, and stimulating placental angiogenesis mediated by VEGF (Thaxton \& Sharma 2010, Brogin Moreli et al. 2012). The fact that its expression increased only in TLR4-deficient mice in response to $I / R$ suggests that it is negatively regulated by TLR4 signaling.

Ifnb1 expression was reduced by $\mathrm{I} / \mathrm{R}$ as well as by TLR4 deficiency independent of I/R. Our data showing decreased Ifnb1 expression in response to $\mathrm{I} / \mathrm{R}$ only in TLR4-competent mice suggests an Ifnb1-regulatory role for TLR4. Intriguingly, Ifnb1 gene expression is the only parameter that exhibited an association with fetal weight changes with respect to i) a decrease upon $I / R$ in wild-type animals, ii) a decreased baseline level in TLR4-deficient animals compared with wild type, and iii) a lack of post-I/R change in TLR4-deficient animals. This close association suggests that TLR4 influences normal fetal growth via a mechanism that involves IFNB1. IFNB1 can regulate prostaglandin biosynthesis (De Cicco Nardone et al. 1996, Kumpfel et al. 2000), and prostaglandins are regulators of placental function. Additionally, IFNB1 can induce the expression of progesterone receptors (Codegoni et al. 1996), which are important in the maintenance of pregnancy. Therefore, it is conceivable that Ifnb1 expression plays a role in supporting fetal growth.

In addition to the above considerations, TLR4 agonists have been found to induce (in human dendritic cells) production of the vasoconstrictive mediator ET-1 (Spirig et al. 2009). We have previously shown that ET-1 is an important mediator of $\mathrm{I} / \mathrm{R}$-induced FGR (Thaete \& Neerhof 2006). It is possible that TLR4 mediates I/R-induced FGR via the downstream stimulation of ET-1 production and that the absence of TLR4 mitigates
FGR induction due to the lack of stimulus of ET-1 expression. This hypothesis remains to be investigated.

Our data suggest an important role for TLR4 during uterine $\mathrm{I} / \mathrm{R}$ in pregnancy. TLR4-deficient mice demonstrate a high incidence of fetal loss, by both premature delivery and IUFD, in response to $\mathrm{I} / \mathrm{R}$. In human pregnancy, $\mathrm{I} / \mathrm{R}$ might be encountered in uterus and placenta because of suboptimal vascular remodeling leading to an imbalance of tissue perfusion-related nutrient and gas supply-and-demand. Additionally, an inadequately regulated inflammatory response may further aggravate this imbalance. TLR4 can react to endogenous ligands (e.g. LMW-HA) that provide 'danger signals' (Kim et al. 2005) produced when perfusion to the tissue is restricted. Activation of TLR4 signaling may produce an inflammatory reaction that could lead to FGR. Subsequently, as 'danger signals' disappear and TLR4 is no longer activated, perfusion may again improve. A temporary risk of FGR might be the cost of preservation of the pregnancy. However, if the system is deprived of the sensor (i.e. TLR4), the reproductive organs may not react with adequate precision to protect the pregnancy.

The importance of TLR4 in a physiological response to danger can be seen in our and others' previous work with heat-killed Escherichia coli in a mouse pregnancy model. Heat-killed E. coli is rich in LPS, an important exogenous ligand for TLR4. LPS, at a relatively high dose, induces premature birth, but only in TLR4-competent mice (Wang \& Hirsch 2003). In contrast, when LPS is given below this level, it causes not premature birth but FGR (Xu et al. 2005). Taken together, this suggests a graded response by the sensor to the level of danger present.

Further insights into the response by TLR4 to $\mathrm{l} / \mathrm{R}$-induced sequelae have been revealed in reported investigations of hypoxia-inducible factor- $1 \alpha$ (HIF-1 $\alpha$ ). Hypoxic tissue responds with HIF-mediated counter measures, e.g. expression of vascular endothelial growth factor and endoglin, which stimulate angiogenesis and regulate metabolism (Sainson \& Harris 2006). It has been found that TLR4 is a regulator of HIF activation: LPS-induced TLR4 activation leads to downregulated HIF- $1 \alpha$ degradation; thus, it ensures prolonged HIF- $1 \alpha$ signaling (Nicholas \& Sumbayev 2010). In the absence of a TLR4 response, the HIF- $1 \alpha$ signal could be inadequate to prevent oxidant injury (Zhang et al. 2005). These reports, along with our findings, emphasize the importance of a functional TLR4 response in the setting of $\mathrm{I} / \mathrm{R}$.

Our results also implicate endogenous TLR4 ligands in the response to $\mathrm{I} / \mathrm{R}$. I/R can induce inflammation (Clarkson et al. 2005), an established observation supported by our MPO data, both in this study and in the one reported earlier (Qu et al. 2012). Based on the observation of a significant increase in uterine MPO in I/R-treated wild-type animals, and the lack of such increase in I/R-treated TLR4-deficient animals, 
we investigated the possibility that TLR4 activation was produced by an endogenous ligand in this model. Our study demonstrated that TLR4 signaling mediates I/R-induced FGR through the action of an endogenous TLR4 ligand, LMW-HA. This was shown by the protective effect of Pep-1 (which specifically blocks LMW-HA binding to and activation of TLR4) against $\mathrm{I} / \mathrm{R}$-induced FGR in $\mathrm{C} 3 \mathrm{H} / \mathrm{HeOuJ}$ animals. Because Pep-1 blocks the interaction of LMW-HA and TLR4, it could thus be concluded that the I/R-induced FGR in $\mathrm{C} 3 \mathrm{H} / \mathrm{HeOuJ}$ mice is mediated at least in part by the interaction of LMW-HA with TLR4.

$\mathrm{C} 3 \mathrm{H} / \mathrm{HeJ}$ mice exhibit an inherent FGR compared with $\mathrm{C} 3 \mathrm{H} / \mathrm{HeOuJ}$. The histological evidence of extensive calcification in TLR4-deficient placentas provides a basis for the reduced fetal growth in these mice compared with their TLR4-competent counterparts. A previous ultrasonic study of normal mouse pregnancy found almost no placental calcification at term (Akirav et al. 2005). Preterm placental calcification in humans has been shown to be associated with reduced uterine and placental blood flow and adverse pregnancy outcomes, including low birth weight (Chen et al. 2012). Reduced placental efficiency due to calcification in TLR4-deficient mice may normally be accommodated by moderately reduced fetal growth. The added stress that results from $\mathrm{I} / \mathrm{R}$-induced sequelae may drive fetal development toward growth restriction in both strains, but while the $\mathrm{C} 3 \mathrm{H} / \mathrm{HeOuJ}$ fetuses have the ability to survive in spite of metabolic stress (albeit with reduced growth), $\mathrm{C} 3 \mathrm{H} / \mathrm{HeJ}$ fetuses have less margin for adaptation and the added stress of ischemia easily produces fetal demise rather than further growth restriction.

Finally, our study introduces into the investigation of FGR an $\mathrm{l} / \mathrm{R}$-induced growth restriction model in the mouse. It features development of FGR and an inflammatory response (demonstrated at the molecular level by our MPO data) in both horns of the uterus in response to transient $\mathrm{I} / \mathrm{R}$ challenge in one horn of the uterus, with no significant differences in the resultant effects between the challenged and unchallenged horns. This corresponds to what we have observed in the rat (Thaete \& Neerhof 2006). This mouse model is especially significant because it facilitates the introduction of genetically altered animals into the study of I/R-related developmental pathology at the molecular level, a prospect that was seriously restricted by the limited availability of genetically altered rats. We expect to see its further application in future investigations of I/R-related reproductive pathology.

\section{Materials and Methods}

\section{Animal experiments}

LPS-hyporesponsive TLR4-mutant $(\mathrm{C} 3 \mathrm{H} / \mathrm{HeJ})$ and wild-type $(\mathrm{C} 3 \mathrm{H} / \mathrm{HeOuJ})$ male and virgin female mice were purchased from Jackson Laboratories (Bar Harbor, ME, USA) and housed in the NorthShore University HealthSystem Research Institute Center for Comparative Medicine in $12 \mathrm{~h}$ light: $12 \mathrm{~h}$ darkness cycles with free access to a standard laboratory rodent diet and water. Timed pregnancy was produced through overnight mating of 11 - to 20 -week-old females in estrus. All animal experiments were in full compliance with the guidelines of and approved by the Animal Care and Use Committee of the Research Institute.

In previous rat studies, transient unilateral uterine $\mathrm{I} / \mathrm{R}$ challenge has proven effective for inducing FGR when conducted during early logarithmic growth (Thaete \& Neerhof 2006). This rat model is useful because it mimics the imbalance of supply/demand for blood perfusion in gestational tissue. This procedure is well tolerated by the treated animals, and the pathological effect is generally manifested as reduced fetal and/or placental weight. To test whether this model works in the mouse, we employed a similar procedure (clamping uterine and ovarian arteries to one of the two uterine horns) to restrict blood flow to the gestational tissue, followed by removal of the arterial clips $30 \mathrm{~min}$ later to establish reperfusion. The challenge was conducted on the 15th day of gestation (term $=\sim 20$ days in these strains of mice), which is developmentally approximately the equivalent of the rat at gestation day 17 .

The pregnant females (weight range 28-36 g) of each strain were divided into two groups of 15 mice each. On the 15th day of gestation, they were anesthetized with a single i.p. dose of xylazine and ketamine, 10 and $100 \mathrm{mg} / \mathrm{kg}$ respectively. The right uterine horn was exposed through a midline abdominal incision for one of the following: i) transient unilateral uterine $\mathrm{I} / \mathrm{R}$ challenge in which the uterine and ovarian arteries to the right horn of the uterus were clamped with two artery clips. The uterine horn was then returned to the abdominal cavity, with the occlusion clips in place until their removal 30 min later for the initiation of reperfusion. The abdominal incision was then closed with sutures and staples. ii) Sham surgery in which the same procedure was followed as for the $\mathrm{I} / \mathrm{R}$ treatments except for omission of artery clamping. On the basis of preliminary experiments, we determined that there was no impact of the sham procedure on fetal growth; therefore, untreated control groups were deemed unnecessary and the use of sham control groups was considered most appropriate.

The animals were inspected twice daily after surgery for documentation of premature delivery. Four days after the surgery (the 19th day of gestation), the animals were killed and dissected. The weights of fetuses and their associated placentas, and the number of resorptions (small dark nodule attached to placenta, not fully formed) and stillbirths (full- or near-term fetuses that are not alive at term) in each horn of the uterus were documented. Tissue samples of uterus and placenta were collected, snap frozen in liquid nitrogen, and stored at $-80{ }^{\circ} \mathrm{C}$ for further analysis.

In a separate set of experiments, to test the hypothesis that I/R-induced FGR is mediated by LMW degradation byproducts of HA (LMW-HA, known to be endogenous TLR4 ligands (Wu et al. 2007)), we examined the effect of the specific LMW-HA inhibitor Pep-1, a specific inhibitor of the interaction 
of LMW-HA and TLR4 (Mummert et al. 2000, Taylor et al. 2004). Four groups of pregnant wild-type (C3H/HeOuJ) mice were treated as follows (5-7 per group): i) sham surgery + Pep-1 (New England Peptide, Gardner, MA, USA) at $1 \mathrm{mg} / \mathrm{mouse}$ per day through one bolus i.p. injection per day for 3 consecutive days, starting 30 min before surgery; ii) sham surgery $+\mathrm{SP}$ (New England Peptide) given in the same fashion as Pep-1; iii) $I / R$ challenge + Pep- 1 , and iv) $I / R$ challenge $+S P$. Fetal weight data were collected on the 19th day of gestation (4 days post-I/R).

\section{Measurement of tissue MPO activity}

A functional assay for MPO (a marker enzyme for activated neutrophils (Klebanoff 2005)) was performed according to a method published previously (Remick et al. 1990). In brief, tissues were homogenized in $0.05 \mathrm{~mol} / \mathrm{l}$ potassium phosphate buffer containing $0.5 \%$ hexadecyltrimethyl-ammonium bromide (Sigma) and EDTA (5 mmol/l) and then sonicated. An aliquot was mixed with substrate $(O$-dianisidine $\mathrm{HCl}$ (Sigma) + $\mathrm{H}_{2} \mathrm{O}_{2}$ in potassium phosphate buffer) and its optical density read at $460 \mathrm{~nm}$. A standard curve was constructed with serial dilutions of human MPO (Sigma).

\section{Semiquantitative mRNA assay for four cytokines}

Total RNA was extracted from uterine tissue using RNA STAT-60 (TEL-TEST, Friendswood, TX, USA) and cDNA was prepared using Moloney-murine leukemia virus reverse transcriptase (Invitrogen). We conducted a preliminary PCR array screen (Qiagen) of mouse inflammation-related genes in uterine tissue. This screening assay was conducted according to the manufacturer's directions and was analyzed using their online PCR array analysis program (http://www.sabiosciences.com/ dataanalysis.php). Array results from three sham and three I/R-treated wild-type animals revealed a significant difference between the sham and I/R groups for four cytokines in the uterus. We then examined mRNA expression of these four cytokines in all the mice by RT-PCR, using standard primer/ Taqman probe sets (Applied Biosystems) for the following mouse genes: interferon-gamma (Ifng, kit \#Mm99999071_m1); interferon-beta 1 (Ifnb1, kit \#Mm00439552_s1); interleukin 10 (I/10, kit \#Mm00439616_m1); interleukin 6 (I/6, kit \#Mm00446190_m1); and 18S rRNA (Taqman rRNA control reagents). All PCRs were conducted using the reaction system and thermal profile recommended by the manufacturer. The mRNA expression was evaluated using $C t$ values, and the results were normalized against $18 \mathrm{~S}$ rRNA in the same sample, as published previously (Thaete \& Neerhof 2006).

\section{Placental histology}

In a separate set of experiments, all placentas from three I/R and three sham-treated mice of both strains were collected at gestation day 19 and fixed in 10\% neutral buffered formalin. These tissues were processed for paraffin-embedding, sectioning, and hematoxylin and eosin staining and then examined by light microscopy for histological comparison. Three placentas from each of three mice from each group were examined.

\section{Statistical analysis}

Fisher's exact analysis was employed for the comparison of premature birth and stillbirth numbers in different treatment groups. One-way ANOVA (with post hoc Bonferroni test) was employed for the comparison of mean values in multiple groups, with $P<0.05$ considered statistically significant. The results in I/R-challenged horns (right side) and unchallenged horns (left side) were acquired separately and were nearly identical (no statistically significant difference by $t$-test between the two sides); therefore, the data presented have been combined from both right and left horns and are displayed in the figures as mean \pm s.E.M.

\section{Declaration of interest}

The authors declare that there is no conflict of interest that could be perceived as prejudicing the impartiality of the research reported.

\section{Funding}

This work was supported by a pilot grant to X-W Qu and a research career development award to $L$ G Thaete from NorthShore University HealthSystem Research Institute.

\section{References}

Akirav C, Lu Y, Mu J, Qu DW, Zhou YQ, Slevin J, Holmyard D, Foster FS \& Adamson SL 2005 Ultrasonic detection and developmental changes in calcification of the placenta during normal pregnancy in mice. Placenta 26 129-137. (doi:10.1016/j.placenta.2004.05.010)

Arumugam TV, Okun E, Tang SC, Thundyil J, Taylor SM \& Woodruff TM 2009 Toll-like receptors in ischemia-reperfusion injury. Shock 32 4-16. (doi:10.1097/SHK.0b013e318193e333)

Ashkar AA, Di Santo JP \& Croy BA 2000 Interferon gamma contributes to initiation of uterine vascular modification, decidual integrity, and uterine natural killer cell maturation during normal murine pregnancy. Journal of Experimental Medicine 192 259-270. (doi:10.1084/jem. 192.2.259)

Brogin Moreli J, Cirino Ruocco AM, Vernini JM, Rudge MV \& Calderon IM 2012 Interleukin 10 and tumor necrosis factor- $\alpha$ in pregnancy: aspects of interest in clinical obstetrics. ISRN Obstetrics and Gynecology 2012 230742. (doi:10.5402/2012/230742)

Brosens I, Robertson WB \& Dixon HG 1967 The physiological response of the vessels of the placental bed to normal pregnancy. Journal of Pathology and Bacteriology 93 569-579. (doi:10.1002/path. 1700930218)

Chen C-J, Kono H, Golenbock D, Reed G, Akira S \& Rock KL 2007 Identification of a key pathway required for the sterile inflammatory response triggered by dying cells. Nature Medicine 13 851-856. (doi:10.1038/nm1603)

Chen KH, Chen LR \& Lee YH 2012 The role of preterm placental calcification in high-risk pregnancy as a predictor of poor uteroplacental blood flow and adverse pregnancy outcome. Ultrasound in Medicine and Biology 38 1011-1018. (doi:10.1016/j.ultrasmedbio. 2012.02.004)

Clarkson AN, Sutherland BA \& Appleton I 2005 The biology and pathology of hypoxia-ischemia: an update. Archivum Immunologiae et Therapiae Experimentalis 53 213-225. 
Codegoni AM, Landoni F, Lomonico S, Losa G, Mangioni C, Taverna M, Lucchini V \& D'Incalci M 1996 Interferon- $\beta$ can induce progesterone receptors in human endometrial adenocarcinoma. Cancer $\mathbf{7 8}$ 448-453. (doi:10.1002/(SICl)1097-0142(19960801)78:3 <448::AID-CNCR11> 3.0. CO;2-Z)

Collins Y, Tan DF, Pejovic T, Mor G, Qian F, Rutherford T, Varma R, McQuaid D, Driscoll D, Jiang M et al. 2004 Identification of differentially expressed genes in clinically distinct groups of serous ovarian carcinomas using cDNA microarray. International Journal of Molecular Medicine 14 43-53.

De Cicco Nardone F, Rossiello F, lacopino F, Benedetto MT, Cinque B, Dell'Acqua S \& Sica G 1996 Effects of interferon- $\beta$ on steroid receptors, prostaglandins and enzymatic activities in human endometrial cancer. Anticancer Research 16 161-169.

Garite TJ, Clark R \& Thorp JA 2004 Intrauterine growth restriction increases morbidity and mortality among premature neonates. American Journal of Obstetrics and Gynecology 191 481-487 . (doi:10.1016/j.ajog.2004. 01.036)

Gonzalez JM, Xu H, Ofori E \& Elovitz MA 2007 Toll-like receptors in the uterus, cervix, and placenta: is pregnancy an immunosuppressed state? American Journal of Obstetrics and Gynecology 197 296.e1-296.e6. (doi:10.1016/j.ajog.2007.06.021)

Ishimoto H, Natori M, Tanaka M, Miyazaki T, Kobayashi T \& Yoshimura Y 1997 Role of oxygen-derived free radicals in fetal growth retardation induced by ischemia-reperfusion in rats. American Journal of Physiology. Heart and Circulatory Physiology $272 \mathrm{H} 701-\mathrm{H} 705$.

Jiang D, Liang J, Fan J, Yu S, Chen S, Luo Y, Prestwich GD, Mascarenhas MM, Garg HG, Quinn DA et al. 2005 Regulation of lung injury and repair by toll-like receptors and hyaluronan. Nature Medicine 11 1173-1179. (doi:10.1038/nm1315)

Kaufmann P, Black S \& Huppertz B 2003 Endovascular trophoblast invasion: implications for the pathogenesis of intrauterine growth retardation and preeclampsia. Biology of Reproduction 69 1-7. (doi:10.1095/ biolreprod.102.014977)

Kim YM, Romero R, Oh SY, Kim CJ, Kilburn BA, Armant DR, Nien JK, Gomez R, Mazor M, Saito S et al. 2005 Toll-like receptor 4: a potential link between "danger signals," the innate immune system, and preeclampsia? American Journal of Obstetrics and Gynecology 193 921-927. (doi:10.1016/j.ajog.2005.07.076)

Klebanoff SJ 2005 Myeloperoxidase: friend and foe. Journal of Leukocyte Biology 77 598-625. (doi:10.1189/jlb.1204697)

Koga K \& Mor G 2010 Toll-like receptors at the maternal-fetal interface in normal pregnancy and pregnancy disorders. American Journal of Reproductive Immunology 63 587-600. (doi:10.1111/j.1600-0897. 2010.00848.x)

Kumpfel T, Then Bergh F, Pollmacher T, Holsboer F \& Trenkwalder C 2000 Acute effects of interferon $\beta-1 \mathrm{a}$ on plasma cytokine levels in patients with MS. Neurology 55 1231-1233. (doi:10.1212/WNL.55.8.1231)

Lewis R, Ahokas R \& Sibai B 2000 Unilateral uterine ischemia/reperfusion induces oxidative stress with fetal growth restriction in both horns in the rat. American Journal of Obstetrics and Gynecology 182 Ss13 (Abstract 6).

Low JA, Handley-Derry MH, Burke SO, Peters RD, Pater EA, Killen HL \& Derrick EJ 1992 Association of intrauterine fetal growth retardation and learning deficits at age 9 to 11 years. American Journal of Obstetrics and Gynecology 167 1499-1505.

Matzinger P 2002 The danger model: a renewed sense of self. Science 296 301-305. (doi:10.1126/science.1071059)

Mayhew TM, Charnock-Jones DS \& Kaufmann P 2004 Aspects of human fetoplacental vasculogenesis and angiogenesis. III. Changes in complicated pregnancies. Placenta 25 127-139. (doi:10.1016/j.placenta.2003. 10.010)

Miyakoshi K, Ishimoto H, Nishimura O, Tanigaki S, Tanaka M, Miyazaki T, Natori M \& Yoshimura Y 2001 Role of leukocytes in uterine hypoperfusion and fetal growth retardation induced by ischemia-reperfusion. American Journal of Physiology. Heart and Circulatory Physiology 280 H1215-H1221.

Mummert ME, Mohamadzadeh M, Mummert DI, Mizumoto N \& Takashima A 2000 Development of a peptide inhibitor of hyaluronanmediated leukocyte trafficking. Journal of Experimental Medicine 192 769-779. (doi:10.1084/jem.192.6.769)
Nicholas SA \& Sumbayev VV 2010 The role of redox-dependent mechanisms in the downregulation of ligand-induced toll-like receptors 7, 8 and 4-mediated HIF- $1 \alpha$ prolyl hydroxylation. Immunology and Cell Biology 88 180-186. (doi:10.1038/icb.2009.76)

Okamura Y, Watari M, Jerud ES, Young DW, Ishizaka ST, Rose J, Chow JC \& Strauss JF III 2001 The extra domain A of fibronectin activates tolllike receptor 4. Journal of Biological Chemistry 276 10229-10233. (doi:10.1074/jbc.M100099200)

Piper JM, Xenakis EM-J, McFarland M, Elliott BD, Berkus MD \& Langer O 1996 Do growth-retarded premature infants have different rates of perinatal morbidity and mortality than appropriately grown premature infants? Obstetrics and Gynecology 87 169-174. (doi:10.1016/00297844(95)00400-9)

Qu X-W, Jilling T, Neerhof MG, Luo K, Hirsch E \& Thaete LG 2012 Unilateral uterine ischemia/reperfusion-induced bilateral fetal loss and fetal growth restriction in a murine model require intact complement component 5. Journal of Reproductive Immunology 95 27-35. (doi:10.1016/j.jri.2012.04.005)

Remick DG, Strieter RM, Eskandari MK, Nguyen DT, Genord MA, Raiford CL \& Kunkel SL 1990 Role of tumor necrosis factor- $\alpha$ in lipopolysaccharide-induced pathologic alterations. American Journal of Pathology 136 49-60.

Riley JK \& Nelson DM 2010 Toll-like receptors in pregnancy disorders and placental dysfunction. Clinical Reviews in Allergy Immunology 39 185-193. (doi:10.1007/s12016-009-8178-2)

Sainson RC \& Harris AL 2006 Hypoxia-regulated differentiation: let's step it up a Notch. Trends in Molecular Medicine 12 141-143. (doi:10.1016/ j.molmed.2006.02.001)

Salafia CM, Minior VK, Pezzullo JC, Popek EJ, Rosenkrantz TS \& Vintzileos AM 1995 Intrauterine growth restriction in infants of less than thirty-two weeks' gestation: associated placental pathologic features. American Journal of Obstetrics and Gynecology 173 1049-1057. (doi:10.1016/0002-9378(95)91325-4)

Spirig R, Potapova I, Shaw-Boden J, Tsui J, Rieben R \& Shaw SG 2009 TLR2 and TLR4 agonists induce production of the vasoactive peptide endothelin-1 by human dendritic cells. Molecular Immunology $\mathbf{4 6}$ 3178-3182. (doi:10.1016/j.molimm.2009.05.179)

Sung I-K, Vohr B \& Oh W 1993 Growth and neurodevelopmental outcome of very low birth weight infants with intrauterine growth retardation: comparison with control subjects matched by birth weight and gestational age. Journal of Pediatrics 123 618-624. (doi:10.1016/S00223476(05)80965-5)

Tanaka M, Natori M, Ishimoto H, Miyazaki T, Kobayashi T \& Nozawa S 1994 Experimental growth retardation produced by transient period of uteroplacental ischemia in pregnant Sprague-Dawley rats. American Journal of Obstetrics and Gynecology 171 1231-1234.

Tanaka M, Natori M, Ishimoto H, Miyakoshi K, Miyazaki T, Kobayashi T \& Yoshimura Y 1997 Effects of a thromboxane synthetase inhibitor (OKY-046) in an ischemia-reperfusion model of intrauterine growth retardation in Sprague-Dawley rats. Biology of the Neonate 72 181-186. (doi:10.1159/000244482)

Taylor KR, Trowbridge JM, Rudisill JA, Termeer CC, Simon JC \& Gallo RL 2004 Hyaluronan fragments stimulate endothelial recognition of injury through TLR4. Journal of Biological Chemistry 279 17079-17084. (doi:10.1074/jbc.M310859200)

Termeer C, Benedix F, Sleeman J, Fieber C, Voith U, Ahrens T, Miyake K, Freudenberg M, Galanos C \& Simon JC 2002 Oligosaccharides of hyaluronan activate dendritic cells via toll-like receptor 4. Journal of Experimental Medicine 195 99-111. (doi:10.1084/jem.20001858)

Thaete LG \& Neerhof MG 2006 Endothelin and platelet-activating factor: significance in the pathophysiology of ischemia/reperfusion-induced fetal growth restriction in the rat. American Journal of Obstetrics and Gynecology 194 1377-1383. (doi:10.1016/j.ajog.2005.11.019)

Thaxton JE \& Sharma S 2010 Interleukin-10: a multi-faceted agent of pregnancy. American Journal of Reproductive Immunology 63 482-491. (doi:10.1111/j.1600-0897.2010.00810.x)

Wang H \& Hirsch E 2003 Bacterially-induced preterm labor and regulation of prostaglandin-metabolizing enzyme expression in mice: the role of toll-like receptor 4. Biology of Reproduction 69 1957-1963. (doi:10.1095/biolreprod.103.019620) 
Wigglesworth JS 1964 Experimental growth retardation in the foetal rat. Journal of Pathology and Bacteriology 88 1-13. (doi:10.1002/path. 1700880102)

Wu H, Chen G, Wyburn KR, Yin J, Bertolino P, Eris JM, Alexander SI, Sharland AF \& Chadban SJ 2007 TLR4 activation mediates kidney ischemia/reperfusion injury. Journal of Clinical Investigation 117 2847-2859. (doi:10.1172/JCl31008)

Xu D-X, Chen Y-H, Wang H, Zhao L, Wang J-P \& Wei W 2005 Effect of $\mathrm{N}$-acetylcysteine on lipopolysaccharide-induced intra-uterine fetal death and intra-uterine growth retardation in mice. Toxicological Sciences $\mathbf{8 8}$ 525-533. (doi:10.1093/toxsci/kfi300)
Yanagishita M 1994 Proteoglycans and hyaluronan in female reproductive organs. EXS 70 179-190. (doi:10.1007/978-3-0348-7545-5_10)

Zhang X, Shan P, Qureshi S, Homer R, Medzhitov R, Noble PW \& Lee PJ 2005 Cutting edge: TLR4 deficiency confers susceptibility to lethal oxidant lung injury. Journal of Immunology 175 4834-4838.

Received 30 October 2012

First decision 30 November 2012

Revised manuscript received 12 March 2013

Accepted 18 March 2013 